\title{
Wind power under the carbon emissions trading scheme
}

\author{
Liu Xinyu ${ }^{1, \mathrm{a}}$, Liu $\mathrm{Na}^{1, \mathrm{~b}}$ \\ ${ }^{1}$ Shanghai Dianji University, School of Business, Shanghai, China
}

\begin{abstract}
As a market trading mechanism, carbon emission trading plays an important role in effectively reducing the overall cost of carbon emission and achieving the "3060" carbon target.At present, the carbon emission trading mechanism has played a role in the world and become an effective means to promote climate governance.China's energy system has always been a high-carbon, high-coal system. The burning of fossil fuels releases a large amount of $\mathrm{CO}_{2}$, which is the main source of carbon emissions. With the improvement of people's living standards, electricity consumption continues to increase. If we want to achieve a substantial reduction in China's carbon emissions, we need to change the structure of the power generation system, which is dominated by coal.
\end{abstract}

\section{Introduction}

Since the 18th National Congress of the CPC, China has vigorously promoted green and low-carbon development. Air quality has improved significantly, energy conservation and emission reduction have achieved remarkable results, and carbon dioxide emissions per unit of GDP have been reduced year by year.But so far, China is still the world's largest carbon emitter.In 2011, China put forward and carried out the pilot work of carbon emission trading, and officially launched the national carbon trading system in December 2017. The system covers only the power sector, where carbon quotas are based on historical emissions and, in practice, only constrain incremental emissions ${ }^{[1]}$. Wind power generation is a clean and lowcarbon form of power generation that can be used forever. In addition, it has many advantages, such as a wide distribution range, flexible installation and disassembly, and less impact on the ecological environment.The research of Professor Jacobson ${ }^{[2]}$ of Stanford University also shows that the life-cycle average carbon emission of wind power is lower than that of photovoltaic, electrothermal, hydroelectric, nuclear, gas-electric, coalelectric and other power generation technologies.

On September 22, 2020, President Xi Jinping solemnly declared at the 75th Session of the United Nations General Assembly that "China will increase its nationally determined contributions, adopt more effective policies and measures, strive to reach the peak of carbon dioxide emissions by 2030 , and strive to achieve carbon neutrality by 2060." The proposal of "carbon peak, carbon neutral" points out the direction for China to accelerate the reform of energy production and consumption and build a "clean, low-carbon, safe and efficient" energy system.

Looking forward to the next 40 years, wind power generation has a broad prospect and will play a more important role in adjusting the energy structure ${ }^{[3]}$, saving energy and reducing emissions, and promoting sustainable economic development.Then, how to fully develop and utilize wind power generation under the existence of carbon emission trading mechanism, so that the economic and environmental pollution of power grid can reach the optimal state has become a direction of our research, and solving this problem has an important reference value for China to achieve "carbon peak" and "carbon neutral".

\section{Research background}

\subsection{Development status of wind power market in Europe}

As early as in the early 1990s, the European Union put forward plans and targets to vigorously develop wind power, which has become the cheapest mode of electricity generation in Europe ${ }^{[4]}$.From the perspective of the regional development status of the European wind power industry, in 2020, Germany will have the largest installed scale of wind power, and the Netherlands will have the largest newly installed capacity.From the perspective of the proportion of wind power consumption in European countries, Denmark and Ireland have a relatively large proportion of wind power consumption, $48 \%$ and $38 \%$ respectively.

From the perspective of wind power development in various European countries, the UK will be the focus of offshore wind power development from 2021 to 2025, with an average annual installed capacity of 14.6 GW.In terms of onshore wind power development, Germany is the focus of development, and Germany will maintain an average annual installation capacity of 13 GW.Figure 1 shows the change of new and cumulative wind power installations in Europe from 2011 to 2020. Figure 2 and 
Figure 3 show the percentages of new installations and accumulative installations of various European countries.

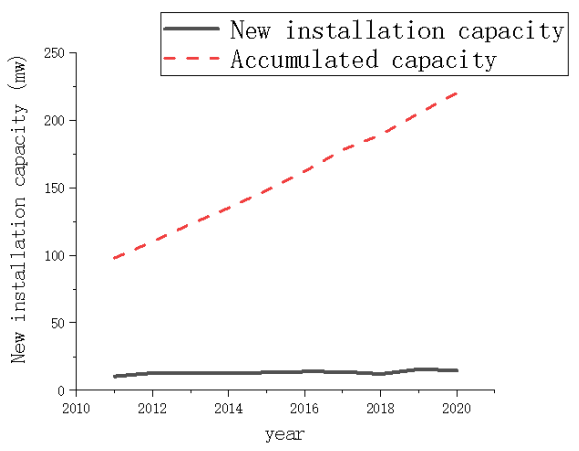

Fig 1. 2011-2020 Changes in new and accumulative wind power installations in Europe

As can be seen from the figure, the Netherlands accounts for the largest proportion of new installations in 2020 , up to $14.14 \%$, followed by Germany, $11.11 \%$, Norway and Spain, both accounting for more than $10 \%$. The accumulative capacity of Germany accounted for the largest proportion, ranked the first in Europe, up to $29 \%$, followed by Spain, the United Kingdom, France, accounting for $12 \%, 11 \%, 8 \%$, the difference is not big.

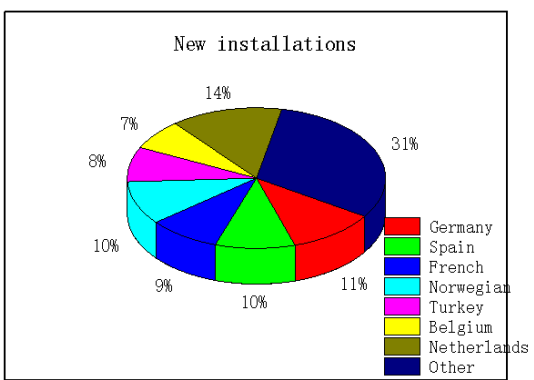

Fig 2. Regional distribution of new wind power installations in Europe in 2020

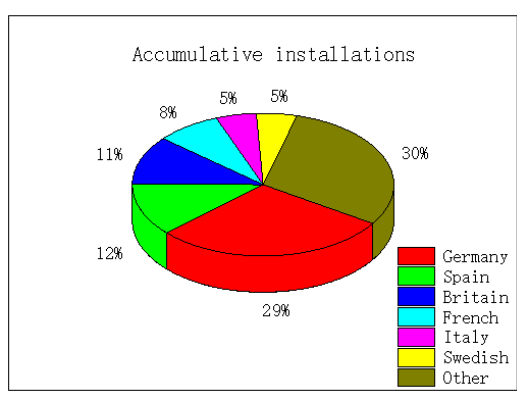

Fig 3. Regional distribution of accumulative wind power installations in Europe in 2020.

\subsection{Development status of China's wind power market}

With the strengthening of environmental regulation in recent years, China has gradually shifted from coal power generation to environmentally friendly wind power generation. Wind power generation has been increasing year by year and has become the main form of wind energy utilization.In 2019, China's wind power generation increased significantly to 405.7 billion kilowatt-hours, with a growth rate of $10.85 \%$.By the end of 2020, China's wind power generation capacity reached 466.5 billion $\mathrm{kWh}$, up $15.1 \%$ year on year.Specific data are shown in Figure 4.

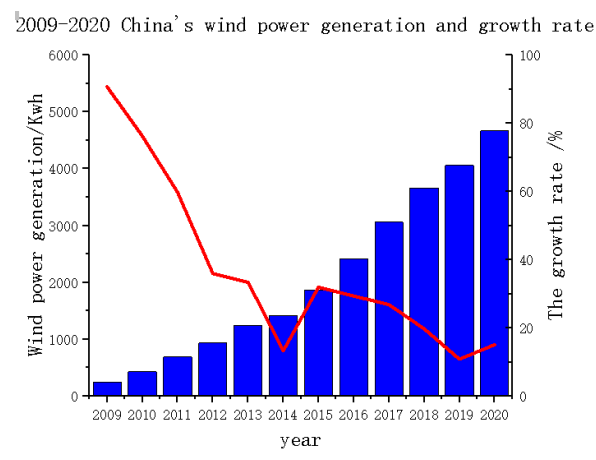

Fig 4. 2009-2020 China's wind power generation and growth rate

\section{Optimization model of wind power consumption under carbon emission trading mechanism and the algorithm}

\subsection{Objective function}

The introduction of carbon trading mechanism changes the marginal cost of thermal power units. In order to maximize the overall benefits of the system under the carbon trading mechanism, the model is built with the profit maximization of thermal power and wind power as the objective.

$$
\begin{gathered}
\max C=C_{1}+C_{2} \\
C_{1}=\sum_{i=1}^{T} \sum_{i=1}^{N}\left(a_{i} P_{G i t}^{2}+b_{i} P_{G i t}+c_{i}\right) \\
C_{2}=\sum_{t=1}^{T} \sum_{i=1}^{N_{w}}\left(d_{i} \cdot p_{w i t}+g_{i} \cdot\left(p_{\text {writ }}-p_{\text {wit }}\right)\right)
\end{gathered}
$$

Where, $C_{1}$ is the operation cost of thermal power unit; $a_{i} 、 b_{i}, c_{i}$ is the coal consumption cost coefficient of No. $\mathrm{i}$ thermal power unit: $\mathrm{T}$ is the number of scheduling periods, take $24 \mathrm{~h} ; \mathrm{N}$ is the total number of thermal power units; $P_{G \text { it }}$ is the output power at time $t$ of the thermal power unit of Unit i. $C_{2}$ is the total operating cost of wind power generation; $N_{w}$ is the total number of wind turbines; $d_{i}$ is the feed-in tariff of the ith wind farm; $g_{i}$ is wind abandonment penalty coefficient of the ith wind farm; $p_{\text {wit }}$ is the grid-connected electric quantity of the ith wind farm at time $\mathrm{t} ; p_{\text {writ }}$ is the predicted output of the ith wind farm at time $\mathrm{t}$.

\subsection{Constraint conditions}

(1) Output constraint of thermal power unit:

$$
P_{G \min i} \leq P_{G i t} \leq P_{G \max i}
$$

(2) Constraint of thermal power unit climbing rate:

$$
-R_{d i} \leq P_{G i t}-P_{G i(t-1)} \leq R_{u i}
$$


(3) Constraint conditions of wind turbine:

$$
0 \leq p_{\text {writ }} \leq p_{w}
$$

\subsection{Improved particle swarm optimization algorithm}

Standard Particle Swarm Optimization Algorithm (PSO), first proposed by Carlson, is an optimized intelligent model inspired by the foraging behavior of birds ${ }^{[5]}$.Different from the original particle swarm optimization algorithm ${ }^{[6]}$, it introduces inertia weight.PSO simulates a kind of constant communication between each individual to change their direction and speed in the search space. In such a process, each individual will constantly learn from successful individuals to make improvements and finally find the target, which is the optimal solution we say.In essence,PSO algorithm is a random search algorithm. When it is used to deal with practical problems, it usually takes the corresponding objective function as the fitness value corresponding to each particle, and determines whether the optimal solution of the problem is reached by comparing it with the previous optimal value of itself and all particles. With the increase of the number of iterations, the fitness value of the particle and the value of the objective function will gradually approach to the optimal solution, and finally get the optimal solution of the problem.

Multi-objective Particle Swarm Optimization (MOPSO) was first proposed by Coello in 2004.The specific implementation steps are as follows ${ }^{[7]}$ :

(1) Randomly generate the initial particle population, calculate the objective function value corresponding to each particle, and add the non-inferior solution to the noninferior solution set;

(2) Find the initial individual optimal value and global optimal value of particles;

Table1. Carbon emission parameters of a thermal power unit in a power plant

\begin{tabular}{|c|c|c|c|c|c|c|c|}
\hline unit & $\mathrm{a}_{\mathrm{i}}$ & $\mathrm{b}_{\mathrm{i}}$ & $\mathrm{c}_{\mathrm{i}} /\left(10^{-5}\right)$ & unit & $\mathrm{a}_{\mathrm{i}}$ & $\mathrm{b}_{\mathrm{i}}$ & $\mathrm{c}_{\mathrm{i}} /\left(10^{-5}\right)$ \\
\hline 1 & 0.00048 & 16.19 & 1000 & 6 & 0.00712 & 22.26 & 370 \\
\hline 2 & 0.00031 & 17.26 & 970 & 7 & 0.00079 & 27.74 & 480 \\
\hline 3 & 0.00200 & 16.60 & 700 & 8 & 0.00413 & 25.92 & 660 \\
\hline 4 & 0.00211 & 16.50 & 680 & 9 & 0.00222 & 27.27 & 665 \\
\hline 5 & 0.00398 & 19.70 & 450 & 10 & 0.00573 & 27.79 & 670 \\
\hline
\end{tabular}

\subsection{Results}

This paper studies how to fully develop and utilize wind power in the presence of carbon emission trading mechanism, so that the economic and environmental pollution of power grid can reach the optimal state.Therefore, we set two situations here. One is that there is no carbon trading mechanism, that is, there is no charge for carbon emissions, and the other is that a charge
(3) The velocity and direction position of particles are updated to form the next new subgroup, and the adjusted individual extreme value is found;

(4) Use the new non-inferior solution set to maintain the external file, form the external file of the next iteration, and select the global extreme value of each particle;

(5) Set $t=t+1$. If the termination condition is met, stop the search; otherwise, return to Step (3).

In view of the problem that the global optimal value is not unique and leads to multiple global extrema in the multi-objective optimization problem, MOPSO algorithm defines the fitness of each population partition region. Firstly, one interval is selected based on the roulette wheel method, and then an external particle swarm individual is randomly selected as the global optimal value.

\section{Example analysis}

\subsection{System parameters}

After wind power generation is connected to the system, the peak pressure of thermal power units increases, and the utilization efficiency decreases accordingly.But relevant studies have shown that the average coal consumption for power generation of thermal power units with wind power is $324.6 \mathrm{~kg} /(\mathrm{kW} \cdot \mathrm{h})$, while the average coal consumption for power generation of thermal power units without wind power is higher $(326.0 \mathrm{~kg} /(\mathrm{kW} \cdot \mathrm{h}))^{[8]}$. This situation is because in the overall view, wind power with small capacity unit utilization rate is still relatively low, improve the overall coal consumption level, from a single unit, the power generation coal consumption is still relatively higher then containing wind power.The statistical results of carbon emission parameters of thermal power units in a certain power plant are shown in Table 1. 
Table2. Wind power and thermal power dispatching results under different conditions

\begin{tabular}{|c|c|c|c|c|c|c|c|}
\hline \multirow{2}{*}{$\begin{array}{l}\text { Carbon } \\
\text { emissions } \\
\text { trading } \\
\text { scheme }\end{array}$} & \multicolumn{3}{|c|}{ Thermal power } & \multicolumn{3}{|c|}{ Wind power } & \multirow{2}{*}{$\begin{array}{l}\text { Profit/ten } \\
\text { thousand Yuan }\end{array}$} \\
\hline & $\begin{array}{l}\text { Power } \\
\text { generation }\end{array}$ & $\begin{array}{l}\text { The } \\
\text { Internet } \\
\text { scale }\end{array}$ & $\begin{array}{l}\text { The power } \\
\text { supply coal } \\
\text { consumption }\end{array}$ & $\begin{array}{l}\text { Power } \\
\text { generation }\end{array}$ & $\begin{array}{l}\text { The } \\
\text { Internet } \\
\text { scale }\end{array}$ & $\begin{array}{l}\text { Abandon the } \\
\text { wind rate }\end{array}$ & \\
\hline No & 47976.2 & 59.4 & 423.5 & 26942.4 & 40.6 & 12.4 & 438.9 \\
\hline Yes & 43834.3 & 57.2 & 421.2 & 29374.6 & 42.8 & 10.6 & 416.2 \\
\hline
\end{tabular}

As can be seen from Table 2, with the introduction of the carbon trading mechanism, the power generation of wind power increases, the wind abandonment rate decreases, but the profit decreases. This part of the reason and the solution to the improvement need further study.

The figure below shows the variation of power generation of thermal power units with or without the existence of carbon trading mechanism.As can be seen from the figure, the introduction of carbon trading mechanism will change the marginal cost of thermal power units, and their generating capacity will also change, but there is no obvious change due to the constraints of unit output.

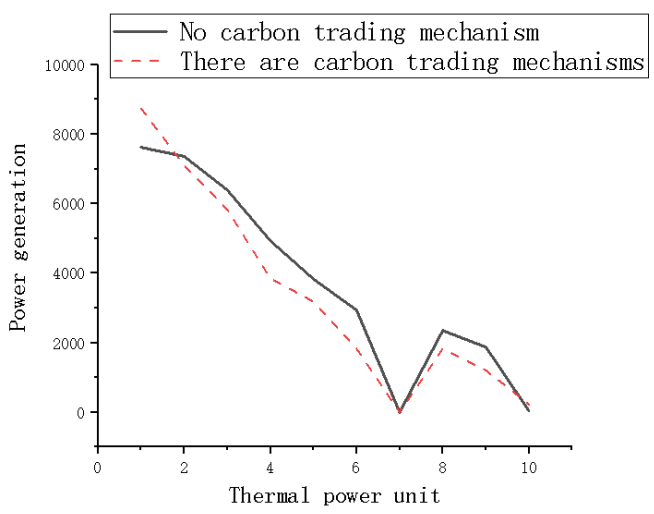

Fig 5. Power generation of thermal power units with or without carbon trading mechanism

\section{Conclusion}

The development and utilization of wind power can effectively reduce China's dependence on fossil energy (especially thermal power) and greatly reduce carbon dioxide emission intensity.It can be seen from this paper that in order to adapt to the current policy, the introduction of carbon emission trading mechanism, the construction of the use of wind power under the carbon emission trading mechanism, through the adjustment of carbon emission rights and trading prices, to achieve the parallel results of low carbon and economy. The final results show that after the introduction of carbon emission trading mechanism, the carbon emissions of thermal power units gradually decreased, and the utilization level of wind power gradually improved.

\section{References}

1. Wang Qian. Wind power installed scale and $\mathrm{CO} 2$ emission reduction forecast in China from 2020 to 2060 [J]. Ecological Economics, 1-17.

2. Evaluation of Proposed Solutions to Global Warming, Air Pollution, and Energy Security [J]. Energy \& Environmental Science, 2019.

3. LI Zheng, CHEN Siyuan, DONG Wenjuan, et al. Research on low-carbon transformation path of power industry under carbon constraint $[\mathrm{J}]$. Proceedings of the CSEE, 1-15.

4. He Puyu, Wei Jiaxiong, Yang Dingli, et al. Research on optimization model of lower wind power consumption assisted by carbon trading mechanism [J]. Hydropower and Energy Science, 2015, 33(02): 205-208.

5. Razali N M M, Hashim A H. Backward reduction application for minimizing wind power scenarios in stochastic programming [J]. IEEE,2010,430-434.

6. Wang Liming. Research on optimal scheduling of isolated microgrid based on particle swarm optimization [J]. Electrical technology,2020 (04) : 55 to 57.

7. Xiao Haibo. Joint dispatching of water-thermal power system based on improved particle swarm optimization algorithm [D]. North China Electric Power University,2015.

8. Coello C,Pulido G T, Lechuga M S. Handling multiple objectives with particle swarm optimization $[\mathrm{J}]$.

IEEETransactionsonEvolutionaryComputation,2004, 8(3):256-279. 